Rhode Island College

Digital Commons @ RIC

$1-1-2014$

\title{
A Nurse-Driven, Exercise-Based Intervention for Patients with Cancer-Related Fatigue when Severe Fatigue Interferes with Daily Activity
}

Nancy B. Opaluch-Bushy

Rhode Island College

Follow this and additional works at: https://digitalcommons.ric.edu/etd

Part of the Other Nursing Commons

\section{Recommended Citation}

Opaluch-Bushy, Nancy B., "A Nurse-Driven, Exercise-Based Intervention for Patients with Cancer-Related Fatigue when Severe Fatigue Interferes with Daily Activity" (2014). Master's Theses, Dissertations, Graduate Research and Major Papers Overview. 244.

https://digitalcommons.ric.edu/etd/244

This Major Paper is brought to you for free and open access by the Master's Theses, Dissertations, Graduate Research and Major Papers at Digital Commons @ RIC. It has been accepted for inclusion in Master's Theses, Dissertations, Graduate Research and Major Papers Overview by an authorized administrator of Digital Commons @ RIC. For more information, please contact digitalcommons@ric.edu. 
A NURSE-DRIVEN, EXERCISE-BASED INTERVENTION FOR PATIENTS WITH

CANCER-RELATED FATIGUE WHEN SEVERE FATIGUE

INTERFERES WITH DAILY ACTIVITY

by

Nancy B. Opaluch-Bushy

A Major Paper Submitted in Partial Fulfillment

of the Requirements for the Degree of

Master of Science in Nursing

in

The School of Nursing

Rhode Island College

2014 


\begin{abstract}
Cancer affects more than 1 million people each year. Of all of the symptoms related to cancer, the most frequently experienced is fatigue. Cancer-related fatigue (CRF) is an extreme tiredness that contributes to morbidity and mortality due to resulting inactivity. Extreme inactivity related to CRF may cause severe complications affecting multiple body systems. The Oncology Nursing Society (ONS) recommends exercise as the only evidence-based intervention shown to be significant for CRF. The purpose of this project was to provide a nurse-driven, exercise-based intervention to combat severe CRF. The site was an oncology out-patient clinic of a 247 bed Magnet hospital in Providence, RI; no specific intervention for oncology patients with fatigue levels $>4 / 10$ was in place. A program development project was developed that included creating a brochure for patients targeted at CRF, revising clinic treatment sheets for easy intervention documentation, and educating the nurses by means of in-services regarding the project. Nurses' knowledge regarding CRF, when to use the brochure and how to document it improved after the in-service. Potentially, receiving the CRF brochure will enable patients to appropriately manage their fatigue at home. Long term follow up related to the impact of the CRF program on Press Ganey fatigue education scores is indicated.
\end{abstract}




\section{Acknowledgements}

To my Lord and Savior, Jesus Christ without whom my life would be hopeless, and my husband, Dean for his endless support in this endeavor. 


\section{Table of Contents}

Table of Contents................................................

Statement of the Problem.............................................1

Theoretical Framework.............................................. 4

Literature Review............................................... 9

Method......................................................... 21

Results.......................................................... 30

Summary and Conclusion........................................ 32

Implications for the Advanced Practice Nurse............................36

References........................................................... 39

Appendices........................................................... 45

Appendix A: CRF Brochure.................................45

Appendix B: CRF In-service Advertisement......................47

Appendix C: CRF Informational Letter.........................48

Appendix D: CRF Pre/Post In-Service Questionnaire.................49

Appendix E: CRF In-Service/Intervention Evaluation.................50 
A Nurse-Driven, Exercised-Based Intervention for Patients with Cancer-Related Fatigue When Severe Fatigue Interferes with Daily Activity

\section{Statement of the Problem}

One of life's most unrecognized — or possibly unaccepted-paradoxes is that exercise produces fatigue and at the same time enhances energy. Popular belief is that the treatment for fatigue is rest, despite the amount of recent sleep. The truth, however, is that inactivity begets lethargy. Historically, the healthcare philosophy of 'resting in bed' following physically challenging circumstances like childbirth or surgical procedures has led to life-threatening complications such as pneumonia and embolic events. Morbidity and mortality related to inactivity have been well documented in the literature (Ezzati et al., 2006; Halpin, Morales-Suárez-Varela \& Martin-Moreno, 2010; Warburton, Nichol \& Bredin, 2006).

Aside from physician recommendations for “rest”, a person’s inactivity may also be due to fatigue that is a symptom of a condition or disease, such as cancer. Estimates are that in 2012 over one million people will be diagnosed with some form of cancer, and of those, approximately half will result in death (National Cancer Institute [NCI], 2012). Of all of the symptoms related to cancer, the most frequently experienced, yet seldom diagnosed, is fatigue (Escalante, 2012; Mock, et al., 2007). Otherwise known as cancerrelated fatigue (CRF), this extreme tiredness often makes activities of daily living nearly impossible and contributes to inactivity and weakness. A downward spiral of 'the less you do, the less you can do’ may ultimately result in reduction in musculoskeletal strength (Al-Majid \& Waters, 2008; Stricker, Drake, Hoyer \& Mock, 2004; Homeber, 
Fischer, Dimeo Ruffer \&Weis, 2012). Side effects related to inactivity adversely affect all other systems in the body, further complicating one's physical condition. Examples of the intertwined, multisystem effects of prolonged inactivity can be seen in several systems: in the cardiovascular system as weakening of heart muscle well as venous stasis leading to blood clot formation; in the respiratory system, inactivity reduces optimum lung expansion thus, retaining secretions that often leads to atelectasis and pneumonia; in the integumentary system, inactivity can result in pressure over boney prominences and contribute to skin breakdown; in the gastrointestinal system, inactivity may decrease peristalsis, leading to constipation which may in turn may contribute to loss of appetite, improper nutrition, and obesity. Obesity changes fat stores and may create glucose intolerance, leading to diabetes (HCPro, 2012). Lastly, prolonged inactivity often limits socialization that frequently contributes to depression (Homeber et al., 2012). As illustrated, inactivity in itself is similar to cancer, in that if left untreated, it slowly leads to a debilitative or deadly state.

Addressing the treatment of CRF, Oncology Nursing Society (ONS) recommended that of all of the non-pharmacological treatments, exercise is the only evidence-based intervention shown to be significant to combat CRF (National Guideline Clearinghouse, 2011). When focusing on exercise as a treatment of general fatigue, there is supporting evidence that individuals who regularly experience fatigue can increase their energy levels by $20 \%$ and decrease their fatigue by $65 \%$ by engaging in regular, low intensity exercise (University of Georgia, 2008). However, the questions as to how much is too much when advising exercise to a person in light of his disturbing diagnosis, fearful 
treatments, body changes and now debilitating fatigue needs to be considered. In an effort to avoid further stress of the oncology patient, physicians and healthcare providers may be hesitant to recommend it, but in the absence of anemia or other hematological disorders, regular exercise is the treatment for fatigue (Escalante, 2012; Ng, 2010).

Most exercise regimes to combat CRF include going for walks or riding an exercise bicycle, and increasing exercise time as able. However, at times, when the patient's fatigue is extreme, thus making regular exercises impossible and even limiting activities of daily living, there needs to be an alternate, easily available intervention that will keep muscles toned and reduce the effects of inactivity. The purpose of this project is to provide an intervention that is a nurse-driven, exercise-based program to combat severe CRF that otherwise limits the performance of daily activity. Operationalizing this project requires that nurses are cognizant of oncology patients' fatigue levels and support patients with severe fatigue by providing them CRF education and an exercise regime that will assist them to manage their fatigue at home. By utilizing the CRF exercise intervention regularly, oncology patients will potentially reduce their risk for suffering adverse effects related to inactivity. 


\section{Theoretical Framework}

Since daily, or at least regular, exercise has been shown to be effective in combating the effects of CRF, exercise is the prescription for promoting and preserving a healthy life. Regular exercise should become as customary as washing oneself or brushing one's hair; in other words, it must become part of one's daily self-care. A theoretical framework that guides health care professionals in their quest for their patients' success in self-care is Dorothea Orem's Theory of Self Care (Nursing Theories, 2012). Orem's general theory of nursing is a grand nursing theory. It is made up of a triad of suppositions: The Theory of Self Care; the Theory of Self Care Deficit; and the Theory of Nursing System (Nursing Theories). For the purposes of this project, the focus will be on the Theory of Self Care.

According to Dorothea Orem (1980) "Self-care has a purpose. It is action that has pattern and sequence and when it is effectively performed contributes in specific ways to human structural integrity, human functioning and human development” (p. 37). Thus, the importance of attaining self-care cannot be understated. Using Orem's theory, activities to achieve self-care are called self-care requisites (Orem, 1980). Specific to this study, the self-care requisite for a patient with CRF (whose recommendation for self-care is exercise) is to perform specific activities or exercises daily.

The methods for meeting particular self-care requisites are described by Orem (1980) in terms of (1) general method and (2) required actions. In this example, the "general method" is musculoskeletal movement (physical activity or exercise) that is possible for most people as a function of life. The "required action" identifies the detailed actions 
taken to achieve partial results toward accomplishing one particular self-care behavior. In this case, it is performing specific repetitive movements, or exercises. The self-care requisites (ie. specific exercises) that are performed by the patient over time to meet the self-care behavior are called therapeutic self-care demands (Orem, 1980). Whether the patient is able to carry out the demands cannot be known until they are implemented.

Predicting the success of accomplishing therapeutic self-care demands can be done by considering Orem's six major assumptions. The assumptions include: people should be self-reliant and responsible for their own care and others in their family needing care; people are distinct individuals; nursing is a form of action - interaction between two or more persons; successfully meeting universal and development self-care requisites is an important component of primary care prevention and ill health; a person's knowledge of potential health problems is necessary for promoting self-care behaviors; and self-care and dependent care are behaviors learned within a socio-cultural context (Nursing Theories, 2012).

Definitions of phrases included in the theory include:

- Self-care is the practice of activities that an individual initiates and performs on his own behalf in maintaining life, health and well-being.

- Self-care agency is a human ability which is the ability for engaging in self-careconditioned by age development state, life experiences sociocultural orientation health and available resources. 
- Therapeutic self-care demand is the totality of self-care actions to be performed for some duration in order to meet self-care requisites by using valid methods and related sets of operations and actions.

- $\quad$ Self-care requisites are the actions directed towards provision of self-care. 3 categories of self-care requisites area include:

o Universal self-care requisites-associated with life: need for air, water, food, activity and rest, and hazard prevention.

o Developmental self-care requisites-are associated with human developmental processes, conditions and events that occur during various stages of the life cycle (Orem, 1980). It is made up of two sub categories: maturational, which involves adjusting to a higher level of development, such as coping with body changes; and situational, which is adjusting to a new experience such as a new job.

o Health deviation self-care requisites- being aware of illness and what to do about it-treat or manage it or seek medical assistance. If a patient is unable to meet their self-care requisites, a "self-care deficit" occurs. In this case, the patient needs health care support which can be total compensation, partial compensation, or education and support. (Nursing Theories, 2012; Nursing Theory, 2011)

In the health care arena, the provision of nursing assistance should be an activity that is assessed according to the present condition of the individual. In a book of Dorothea Orem’s papers edited by Repenning \& Taylor (2003), Ms. Orem wrote: 
"The design of a system of nursing assistance is a plan for nursing in its essential outline. If one accepts that a nurse may contribute to (1) accomplishing the self-care of the patient in a therapeutic manner when a patient's limitation must be compensated for and (2) overcoming a patient's present limitations, it is possible to narrow action down to four types. By the arrangement of these types there are four basic designs for nursing action: wholly compensatory, partly compensatory (supportive), supportive-educative and compensatory-educative” (p. 61).

According to this, the nurse providing education to the patient and his support person about home exercise is in the supportive-educative role or the compensatoryeducative role, depending on the independence the patient exhibits with the exercise regimen/self-care. Orem (1980) believes that every individual adult, given appropriate instruction, has the capacity for self-care. However, when a health problem arises, it is possible that this capacity is insufficient to confront the condition, making it necessary to seek help from others who can compensate for any deficit.

This project proposal offers an intervention comprised of information and exercises for severe CRF that patients perform daily while at home. The intervention follows Orem's major assumptions as seen in oncology patients, identifying a support person to whom they will be held accountable or by whom they will be assisted to perform the intervention exercises. Each patient will receive individualized instruction or reinforcement of the program from a clinic nurse when fatigue levels have prevented him/her from performing regular activities or exercises. In seeing nursing as a form of action - interaction between two or more persons, the clinic nurses will communicate, 
educate, and assist the patients and their support persons as needed. Each clinic nurse will instruct and demonstrate exercises to the patient and his support person. Return demonstration of the information and exercises will be expected of the patient. Educating the patient about potential health problems to promote self-care behaviors will be satisfied by an informational pamphlet provided to the patient that will be reviewed by the nurse.

By applying Ms. Orem’s Theory of self-care to the oncology patient who needs to perform regular/daily exercise in an effort to combat fatigue, the nurses' role is supportive and educative: supportive in that they assist in identifying a support person who will accept the role; educative by supplying the patients and their support persons with information on CRF circumstances that lead to the condition and consequences of noncompliance. In addition, the clinic nurses will educate and demonstrate exercises and expect the patient to return the demonstration of information. By utilizing the Self-Care Theory, patients will take responsibility and regain a sense of control over their life by having an appropriate arsenal with which to battle their fatigue.

Literature used for this project will be addressed. 


\section{Literature Review}

A literature review was performed using the MEDLINE , OVID, UpToDate, and CINAHL databases and using key words inactivity, exercise, cancer, cancer statistics, oncology, fatigue, cancer-related fatigue, fatigue scale, activity, resistance exercise, muscle strength, muscle wasting, and quality of life. The search was limited to the materials written in English from 1995- present.

\section{Introduction: Cancer and Cancer-Related Fatigue}

In 2012, it was estimated that $1,638,910$ Americans would be diagnosed with some form of cancer. Of those diagnosed, 577,190 would succumb to the disease (National Cancer Institute [NCI], 2012). For those who have cancer, cancer-related fatigue (CRF) is the most distressing and life-altering side effect of cancer and cancer treatments (Escalante, 2012). The fatigue that CRF sufferers experience can be so debilitating that it may inhibit them from returning to normal daily, societal, and occupational activities following cancer treatment, resulting in devastating economic and social consequences (Dimeo, 2001). Reduced concentration and loss of interest in pastimes further negatively affects significant activities in the lives of cancer patients that keep them active and emotionally engaged. This predisposes them to mood disturbance and depression (Horneber, 2012), and for those who experience survivorship, it may mean a lifetime of continuing to struggle.

\section{Cancer-related Fatigue: Definition}

According to the National Comprehensive Cancer Network Guidelines (2014)

"Cancer-related fatigue is a distressing, persistent, subjective sense of physical, 
emotional, and/or cognitive tiredness or exhaustion related to cancer or cancer treatment that is not proportional to recent activity and interferes with usual functioning” ( p. FT-1). This problem ominously impacts the quality of life of between $15-90 \%$ of cancer patients; the reason for the wide range of the estimates is likely due to inconsistent diagnostic benchmarks (Escalante, 2012). Clinical features of CRF include tiredness ranging from lack of energy to exhaustion, loss of drive and personal interests, as well as impaired memory and concentration. The multi-factorial etiology and pathogenesis is related to cancer/tumor type, treatments experienced, genetic disposition to physical and emotional stress, as well as conditions experienced such as anxiety and sleeplessness (Hormeber, Fischer, Dimeo, Ruffer, \& Weis, 2012). In addition, CRF is thought to be associated with anemia, poor nutrition and excess analgesia (Cleveland Clinic Cancer Center, 2005). The effects of CRF may persist for months or years after treatments are completed, and often contribute to patients' morbidity and mortality. The problem with CRF is that it often leads to physical inactivity that further exacerbates fatigue by inducing muscular catabolism. This contributes to a cycle of further decline in performance, reduction in activity, and easy fatigability (Dimeo, 2001; Stricker, Drake, Hoyer \& Mock, 2004). Inactivity often leads to deconditioning, a condition that is surprisingly easy to develop even in healthy persons (The Journal of Supportive Oncology’s 2007). Regular physical activity and exercise have many potential benefits for both healthy and unhealthy individuals. 


\section{Benefits of Exercise in Chronic Disease, including Cancer}

Physical activity has been consistently shown to reduce the morbidity and mortality from many chronic diseases (Assistant Secretary for Planning and Evaluation [ASPE], 2003). According to Warburton et al. (2006), there is irrefutable evidence of the effectiveness of regular physical activity in the primary and secondary prevention of several chronic diseases (eg., cardiovascular disease, diabetes, cancer, hypertension, obesity, depression and osteoporosis) and premature death.

Research has demonstrated that virtually all individuals can benefit from regular physical activity, whether they participate in vigorous exercise or some type of moderate health-enhancing physical activity (Wanchai, Armer, \& Stewart, 2011). There is support that physical activity equivalent to walking at least one hour per week was associated with improved survival among cancer patients, compared with patients who did not participate in comparable physical activity (Warburton et al., 2006). Evidence like this has served as a catalyst to encourage Americans to participate in various forms of physical activity as recommended in Healthy People 2020 (U.S. Department of Health and Human Services, 2008). In addition to the benefits to the cardiovascular, respiratory, and musculoskeletal systems (Warburton et al., 2006; The Journal of Supportive Oncology's 2007), researchers have found convincing evidence that physical activity is associated with a reduced risk of cancers of the colon, breast, prostate, lung, and uterus (McNeely et al., 2006; NCI, 2012; Warburton, et al., 2006;). In contrast, immobility is associated with a wide range of negative outcomes that adversely impact people with cancer. 


\section{Consequences of Immobility and Effects on CRF}

Deconditioning is linked to prolonged bed rest. Persistent bed rest results in muscle strength declines of about $10 \%$ per week. Should immobility continue for five weeks, proximal lower extremity muscles may lose as much as $24 \%$ of their force and muscle shortening along with joint contractures may also result (The Journal of Supportive Oncology's 2007). The issues related to inactivity become very complicated when viewed from the perspective of oncology patients who have additional co-morbidities.

In the past, physicians advised patients with cancer to rest and avoid physical activity for comfort reasons (Dimeo, 2001; Velthuis, Agasi-Idenburg, Aufdemkampe, \& Wittink, 2010). However, while avoiding strenuous activity caused less discomfort, the recommended inactivity induced further muscular wasting, resulting in weakness, tachycardia, and breathlessness with minimal activity (Dimeo, 2001). Inactivity-induced muscle weakness compounds the patient's already deconditioned state due to cancerrelated muscle wasting. Skeletal muscle wasting in cancer patients is due to a combination of decreased muscle protein synthesis, pro-inflammatory cytokines, and tumor-released proteolysis-inducing factor. In addition, decreased physical activity and nutritional intake of proteins may also be responsible for the muscle loss (Al-Majid \& Waters, 2008). Muscle wasting and associated weight loss may in turn result in a potential reduction in the responsiveness to cancer treatments and also may cause drug toxicities that contribute to increased morbidity and mortality (Andreyev, Norman, Oates, \& Cunningham, 1998; Attaix et al., 2005). In contrast, preserving muscle tone and 
reducing muscle wasting through regular exercise can contribute to positive outcomes in individuals experiencing CRF.

\section{Impact of Exercise on CRF}

In addition to the physical benefits of exercise, routine physical activity also positively impacts a person's psychological well-being by reducing stress, anxiety, and depression (Warburton et al., 2006). Psychological well-being has been shown to be crucial for the prevention and management of cardio-vascular disease and cancer, as well as other chronic diseases such as diabetes, osteoporosis, hypertension, obesity, and depression (Warburton et al.).

Two comprehensive, systematic qualitative review articles (Friedenreich \& Courneya, 1996; Ream and Richardson, 1999) supported the research-based conclusion that exercise is an effective intervention for CRF. The first was a summary of nine research studies conducted on the topic of exercise and rehabilitation of patients with cancer that identified the needs and proposed directions for further research. The other article reviewed interventions for fatigue and also supported the positive impact of exercise on CRF. The evidence that was uncovered strongly supported the efficacy of moderate exercise as an intervention for CRF in cancer patients as well as cancer survivors. The authors also encouraged oncology nurses to utilize this evidence to their clinical practice, research and education.

In a prospective, descriptive study by Berger and Higginbotham (2000), 14 women with stage I or II breast cancer who were receiving four cycles of chemotherapy were identified for study. Using a variety of measurement methods, variables such as activity, 
sleep, symptom distress, health status and fatigue were assessed during chemo cycles. Findings included a significant decrease in the mean activity levels during and following treatments, and also discovered that highest levels of fatigue and system distress occurred between the third and fourth cycle of chemotherapy. Lower activity was linked with fatigue, greater distress, and poor physical and social health status. Implications for patients are to remain active, manage symptoms and obtain quality sleep, especially in women with poorer health status; this may assist in reducing fatigue.

Stricker et al. (2004) reviewed and summarized the current state of evidence on exercise as an intervention for fatigue management in adults with cancer. Of the 42 articles identified, 21 were selected for review. In addition, 13 research studies were identified and obtained based on a book chapter by Mock (2003). Lastly, three published abstracts that were generated following the annual meetings of the American Society of Clinical Oncology, American College of Sports Medicine (ACSM), Oncology Nursing Society as well as the Seventh National Conference on Cancer Nursing Research were included in the review. All of the identified research reports and case studies, regardless of date, and review articles and reports of practice guidelines from 1995-2003 were included in the systematic review. Articles were required to identify exercise as the intervention and fatigue as an outcome variable. Stricker et al. evaluated nine experimental randomized control trials and 11 quasi-experimental studies with a combined number of 858 subjects. All subjects were receiving cancer treatments during the time of the experiments. Each of the studies provided support in various degrees that exercise was an effective intervention-all reported positive effects of exercise. Positive 
effects were either a reduction in fatigue level of those who participated in exercise as compared to those who did not, or-in hospice patients—-documented stabilization of fatigue experienced by exercising. The exercise group was able to perform regular daily activities with less distress-causing fatigue. In the case of hospice patients, exercising allowed patients to better cope with their disease and daily activities.

A systematic quantitative review of randomized control trials was performed by McNeeley et al. (2006) to examine the effects of exercise interventions on breast cancer patients and survivors. One hundred and thirty-six studies were reviewed, and 14 were identified as meeting the inclusion criteria $(\mathrm{N}=717)$. The RCTs examined exercise interventions for breast cancer patients and survivors. Analyses included QOL, cardiorespiratory fitness or physical functioning as primary outcomes. Many of the RCTs showed positive effects of exercise on QOL using both FACT-G (WMD 4.58, 95\% CI o.35-8.8) and Fact-B (WMD 6.62, 95\% CI 1.12-12.05). Cardiorespiratory fitness, physical functioning, and well-being fitness were measured using peak oxygen consumption in $\mathrm{mL} / \mathrm{kg}$ per minute from symptom-limited graded exercise tests. Pooled results showed improvement in peak oxygen consumption with exercise (WMD 3.39, 95\% CI 1.67-5.10). Of note, there were adverse events from exercise programs that were reported in four studies including back injuries $(n=4)$, shoulder tendinitis $(n=1)$, and lymphedema $(\mathrm{n}=2)$ related to participation in resistance exercises.

When educating the oncology patients about CRF and interventions that are successful at combating it, timing is important to retain information. Wu, Dodd \& Cho (2008) investigated the timing and duration of CRF in relationship to cancer treatments as well 
as the effect of exercise on CRF. They conducted a secondary data analysis of five cancer centers in California; the sample included 98 female out-patients receiving chemotherapy for breast cancer. Data were collected as part of a randomized clinical trial to test the effectiveness of an exercise intervention on fatigue. Inclusion criteria included those 21 years or older, diagnosed with breast cancer and receiving chemotherapy, expected to survive at least 12 months, and able to communicate in English to consent. A fatigue diary using an 11 point rating scale ( $0=$ none; $10=$ overwhelming fatigue) was used to document fatigue and subjects were instructed to complete it at the same time each night. The groups were classified as "exercisers” and “non-exercisers” using the guidelines of exercising at least three days/week for 20 minutes per session at a “somewhat hard” intensity. Fatigue scores were obtained daily for 21 days beginning on the first day of chemotherapy. A rehabilitation program consisting of a walking program and a support group for breast cancer patients was developed. The average levels of fatigue reached a peak on the treatment day followed by a gradual decline and a slight elevation two to three days before the fourth chemotherapy treatment. It was discovered that although the patterns of change in fatigue were similar between "exercisers" and “non-exercisers”, “non-exercisers” consistently reported higher fatigue levels. The peaks of both groups occurred during the third cycle of chemotherapy. These results suggest that teaching should be instituted early in the treatment plan, or otherwise postponed until the treatment regime is farther along and fatigue is diminishing.

With regard to exercise influencing physical performance, a review article by 
Al-Majid \& Waters (2008) found support for the use of progressive resistance exercise training (PRT). This is a type of exercise in which the muscle generates progressively higher force overtime; it is an emerging intervention that may be used to reduce muscle wasting. It was also noted that although still in use, limited research supports improvements in muscle strength associated with PRT exercises in oncology patients.

When focusing on distressing conditions such as cancer and the associated symptom of CRF, patients and their support persons may question whether it is therapeutic to stress an ailing body further with demands such as exercise. Non-pharmacologic supportive strategies, including exercise, that promote quality of life in CRF are crucial in the life of the oncology patient. Wanchai et al. (2011) investigated these strategies in a systematic review. Studies were screened for inclusion criteria and included articles of randomized control trials and quasi-experimental studies concerned with the non-pharmacologic supportive strategies that may enhance or promote the QOL in patients with breast cancer suffering from CRF. Studies were required to have CRF and/or QOL as outcomes of interest. Eighty-nine articles were identified, with 28 meeting the criteria selected for review. Of the 28, 19 focused on patients with breast cancer during treatment and nine were considered breast cancer survivors having completed treatments. Various screening tools were used in the study such as PFS and revised PFS, FACT-Anemia, MFI, Schwartz Cancer Fatigue Scale, Functional Assessment of Chronic Illness TherapyFatigue version IV, Linear analog scale for fatigue, VAS-F, and the FACT-Fatigue. Focusing on non-pharmacologic supportive intervention, the authors identified 17 studies that evaluated the effect of exercise, education/counseling, sleep therapy, and 
complementary therapies. Exercise was composed of supervised workouts (8), homebased exercise (7), and other strategies (trained volunteers) to promote exercise in women with breast cancer. Of the eight supervised exercise programs, four showed that supervision significantly improved QOL and reduced CRF in women with breast cancer. Home-based exercise programs used videotapes and/or printed materials combined with step pedometers. No specific data using the tools was presented; however, it was reported that of the seven home-based exercise programs, all produced consistent findings regarding the effectiveness of home-based exercise to reduce CRF in patients with breast cancer. Based on these results, it may be concluded that home-based exercise during and after cancer treatment should be recommended for patients with breast cancer along the treatment continuum as it may reduce CRF and improve QOL. The admitted weakness of the analysis was that limiting the study to breast cancer patients resulted in a homogenous group, making it difficult to generalize the results.

\section{Barriers to Exercise in CRF}

Many oncology patients, although aware of the benefits of exercise, are not compliant. During episodes of severe fatigue, some patients may view exercise as counterproductive and accept the excuses not to exercise that they receive from friends and family. In an article by Blaney et al. (2010), barriers to exercise of cancer patients were investigated. This exploratory, descriptive, qualitative study employed focus groups to collect data. Using purposive sampling methods, 26 patients with CRF who were representative of the cancer pathway were recruited. All were Caucasian, survivors of cancer, in palliative care, and/or were recently diagnosed and undergoing treatments. The 
mean age of participants was 55 years old. Findings showed that there were considerable changes in participants' physical activity levels pre-diagnosis to post-diagnosis. None of the patients who exercised pre-diagnosis considered themselves even moderately active after treatment. Fatigue and physical deconditioning were major exercise barriers. Lack of confidence regarding self-image and fear of falling were also noted. Because of cancer treatments, some subjects had become deconditioned and unstable, and many felt selfconscious due to hair loss or bowel control issues. In addition, some expressed anxiety about exercising in public places which were germ-infested, especially during cold and flu season, and also were concerned about exercising adjacent to stronger, otherwise healthy-looking people. Lastly, financial issues related to having access to exercise equipment were also identified. For some, gym equipment was not affordable and others felt it was not profitable to have a gym membership as they often were unable to exercise due to the unpredictability of their state of health, fatigue and their generally deconditioned state.

Despite the widespread prevalence of physical inactivity_-knowing the associated health risks, and that increasing physical activity would improve health outcomesclinicians do not routinely screen patients for physical inactivity or provide adequate counseling (Peterson, 2012). Instead, other common non-pharmacological treatments for CRF are offered instead of exercise during times of severe fatigue. And while psychoeducation, cognitive behavioral therapy, energy management, and mindfulness and relaxation techniques are supported by evidence as likely to be effective, exercise is the 
only intervention that is recommended for practice by the ONS (Horneber et al., 2012; ONS, 2008).

In summary, there is support from the literature that exercise is an effective intervention to improve quality of life, cardiorespiratory fitness, physical functioning, and fatigue in cancer patients and survivors. However, it is also evident that when CRF is severe, the sufferers may perceive that they are unable to exercise; the resulting inactivity for a prolonged period of time may result in lethargy, extreme deconditioning and even depression, all of which can contribute to CRF.

The purpose of this project is to develop a nurse-driven, exercise-based program as an intervention to combat severe CRF that would otherwise limit the performance of activities of daily living.

Next, the methods used in this project will be described. 


\section{Method}

\section{Purpose and Goals}

The purpose of this project was to develop and implement a nurse-driven, exercise-based program as an intervention to combat severe CRF that would otherwise limit daily activity. The first step in the process was to develop a brochure (Appendix A) targeted at CRF education and exercise interventions to combat it. Next, oncology nurses and CNAs required education regarding the need for a CRF intervention, information contained in the CRF brochure and indications for its use. Last, the nurses we given instruction how to document that the CRF brochure was provided as an intervention on the present clinic treatment sheets.

\section{Sample and Site}

The target sample included nurse educator team members, oncology clinic staff nurses, and unit-based CNAs employed in the oncology clinic, Fain 3, at The Miriam Hospital (TMH), a 247 bed Magnet hospital in Providence, RI.

\section{Program Development}

Overview of the Logic Model. “The Logic Model or Change Model is a systematic and visual way to present and share your understanding of the relationships among the resources you have to operate your program, the activities you plan, and the changes or results you hope to achieve” (W.K. Kellogg Foundation, 2004, p.1). It was developed and first implemented in the 1970s as a model to guide program development and has undergone many refinements (W.K. Kellogg Foundation). A paradigm for application of the logic model is when deficiencies are noted in a present standard operating procedure. A needs assessment is then performed to identify the deficient area that requires modification, and the Logic Model is then employed. 
The Logic Model is made of up inputs, activities, outputs, outcomes, and impact. Inputs include the human, financial, organizational, and community resources a program has available to perform the work. Activities include the processes, tools, events, technology and actions that are needed for the program implementation. Outputs are the direct products of program activities and may include services to be delivered by the program. Outcomes are the specific changes that occurred as a result of the activities. Examples of a change include participants’ behavior, knowledge, skills, status or level of functioning. And impact is the fundamental intended or unintended change occurring in organizations, communities or systems as a result of program activities.

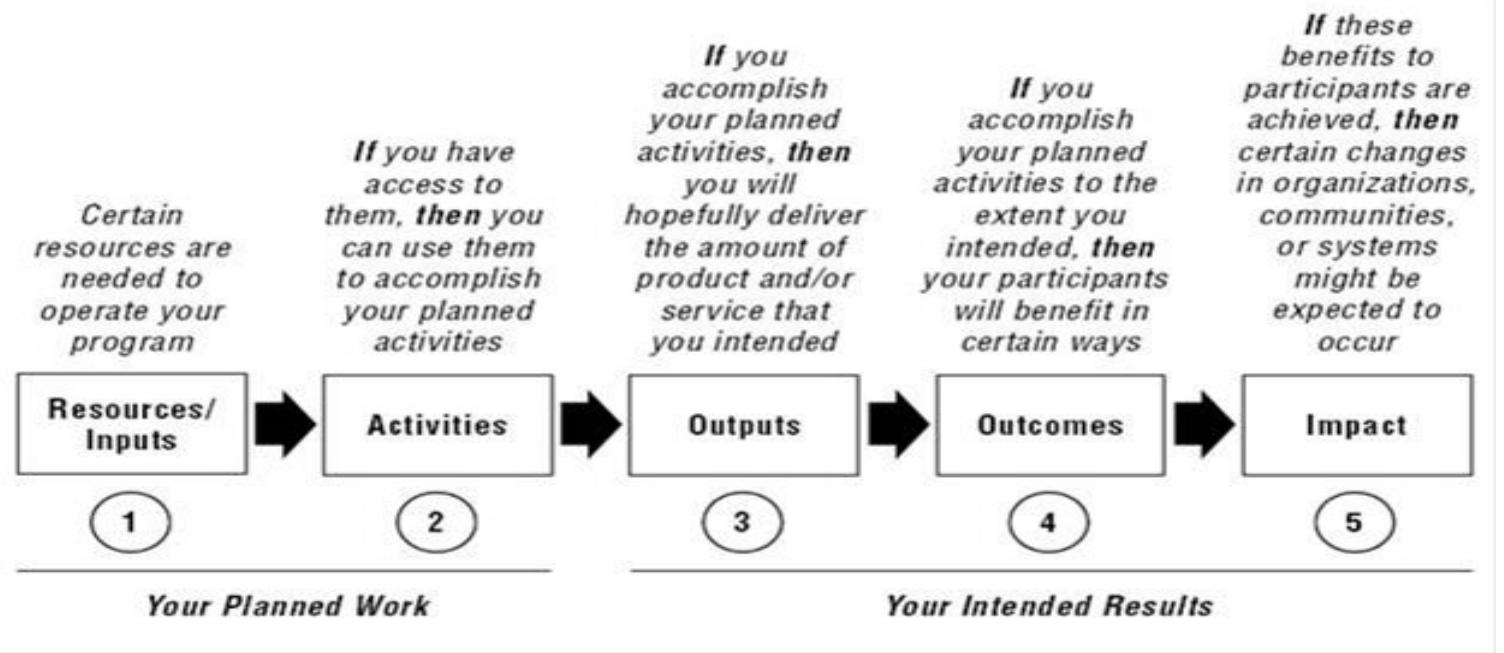

(W. K. Kellogg Foundation, 2004)

Figure 1. Depiction of the Logic Model (W. K. Kellogg, p. 3).

Needs Assessment. Fatigue is a very common side effect of cancer and cancer therapy.

Knowing that, Fain 3 staff had procedures in place to educate and identify potentially hazardous fatigue. Prior to initiating cancer treatment or cancer-related therapy, newly diagnosed patients were scheduled for a comprehensive education session. This session covered the cancer treatment and medications that they would receive, expected side effects and treatment, and all 
supporting programs and contact numbers. This education program appeared to be comprehensive and supportive. However, when the Fain 3 CNS and the student investigator reviewed patient satisfaction/Press Ganey scores for education, more specifically, fatigue education on Fain 3, some unstable trends were identified. Quarterly ratings from 2011-2013, ranged from $81.3 \%$ to $97.7 \%$, and the potential for improvement was identified.

Upon further examination of the education that took place during the initial teaching session, the student investigator noted that cancer patients also had assessments of their baseline activity and fatigue levels completed. Documentation was completed using the Oncology Nursing Society's (ONS, 2008) numeric rating scale for fatigue, which ranges from "no fatigue” (0), "Mild" (1-3), "moderate" (4-6), "extreme" (7-9) to "the worst fatigue imaginable" (10). Prior to cancer treatment, patients were instructed to combat fatigue through daily exercise such as walking, biking, or using an exercise bike. In addition, patients had access to a video library thaincluded Lance Armstrong's Livestrong video on exercise for the oncology patient.

Theoretically, any patient who went to Fain 3 for cancer treatments and divulged a fatigue level of $>4 / 10$ should have received an intervention, or at least advice, on how to treat the fatigue. In addition, it was expected that a narrative nursing note should be completed on the patient's clinic treatment sheet that day to document any strategies that were offered to the patient to combat their fatigue. An important component prior to developing this program was to validate that this indeed occurred, and this was part of the needs assessment that was conducted.

The student investigator attended three teaching sessions of newly diagnosed cancer patients and observed clinic nurses on two regular clinic days. Results showed little or no mention of CRF at the teaching sessions and no noteworthy treatment by the nurses for fatigue that was scored $>4 / 10$ by the clinic patients. In addition, a chart review was completed that focused on 
what nursing interventions were documented for patients who claimed to have moderate to severe fatigue with a score of $>4 / 10$. Findings from the 17 records reviewed supported the prevalence of patients affected by CRF, as only one oncology patient of the 17 reported "no fatigue” during treatments. Of those affected by fatigue at a level of $>4$ out of $10(n=16)$, there was no documentation of interventions by nurses. Because specific documentation was lacking, it was unclear if efforts were made by the nurses to offer the patient interventions to combat this distressing condition.

In summary, at that time, Fain 3 had neither a specific plan for a fatigue intervention in place, nor a simple documentation process for patients with moderate fatigue. Since bothersome fatigue is a common complaint, exploring specific opportunities for improvement was necessary. The deficiencies of the SOP and the erratic Press Ganey scores were discussed with the CNS, resulting in planning a program development project for the treatment of CRF.

Inputs. Inputs include the human, financial, organizational, and community resources a program has available to perform the work. Inputs included the medical team, the nurses and unit-based CNAs, and the oncology patients on Fain 3. The Director of Fain 3 provided support and approval for the project.

Preliminary information about the planned program was sent to the Fain 3 oncologists via email to allow them time to consider its' use for their patients. The program was officially presented to the Oncologists at their monthly clinic meeting. They were receptive to the program with their only suggestion being to choose only one cancer group on which to trial the brochure. However, after a brief discussion with the Director of Ambulatory and Cancer Services, it was agreed that all cancer groups would benefit from the intervention. Formal approval for the project was obtained at that time. After physician approval was obtained, further approval to 
create a brochure for nurses that included CRF education and alternative exercises was obtained from the Director of Ambulatory and Cancer Services and the Fain 3 as well as the Nursing Educator. The nurses and CNAs were then alerted to the upcoming CRF intervention program

Activities. Activities are the processes, tools, events, technology and actions that are an intended part of the program implementation. The content of the brochure was developed from the literature review and with input from the CNS. In addition, the Director of Physical Therapy at TMH was consulted for recommendations related to appropriate exercises for CRF. The Director was able to extrapolate from a similar exercise program that had been initiated elsewhere in the hospital to combat weakness due to immobility. The content was developed using Knowles Adult Learning Assumptions (1970) which include:

- Adults need to have a readiness to learn, that is prompted by understanding the necessity for learning;

- Adults’ experience provides a basis for learning activities:

- Adults are most interested in learning subjects that have immediate relevance to their life;

- Adults are self-directed and need to be responsible for their own decisions;

- Adult learning is performance centered rather than content centered; and

- Adults learn respond better to internal motivators rather than external.

The brochure (Appendix A) was developed to include three informational sections (Table 1). The first section focused on the facts related to what CRF is and the dangers of CRF. The next section depicts exercises for the patients to practice during periods of moderate to severe fatigue. Health literacy issues were considered by utilizing illustrations to depict the activities; lower extremity stretches, range of motion activities, and some exercises are pictured here. Along with the pictures, there are simple descriptions of the movements that assist with understanding the activities. These exercises allow the musculoskeletal system to remain toned and flexible during periods of extreme fatigue when activity may be severely reduced. Finally, there is an exercise 
log to keep track of daily exercises and also serve as a record of compliance. There are instructions that explain how to decide which exercise program to perform that day, taking into account the amount of fatigue that is experienced. By utilizing this intervention, the patients will potentially keep motivated as they track their progress.

Table 1

Major Components of the Exercise Brochure

\begin{tabular}{|l|l|l|}
\hline Part I & Part II & Part III \\
\hline $\begin{array}{l}\text { Education: } \\
\text { Definition/symptoms }\end{array}$ & Exercises: & Exercise Log: \\
\hline Incidence & Range of motion/stretches & Date/Day of chemo cycle \\
\hline $\begin{array}{l}\text { General CRF information and } \\
\text { approaches to combating } \\
\text { fatigue }\end{array}$ & Exercises & Fatigue score \\
\hline $\begin{array}{l}\text { Issues related to inactivity } \\
\text { and/or noncompliance with } \\
\text { exercise }\end{array}$ & & $\begin{array}{l}\text { Logging Exercises: } \\
\text { ROM/Stretches (4) } \\
\text { Exercises (4) }\end{array}$ \\
\hline $\begin{array}{l}\text { Exercise as the recommended } \\
\text { treatment }\end{array}$ & & \\
\hline $\begin{array}{l}\text { Scoring fatigue } \\
\text { using the exercise log }\end{array}$ & & \\
\hline $\begin{array}{l}\text { Explanation of exercises and } \\
\text { und }\end{array}$ & & \\
\hline
\end{tabular}

Permission to carry out the project was granted by the Rhode Island College IRB as well as Lifespan IRB. Shortly after, an advertisement of the project (Appendix B) and an in-service schedule was posted on Fain 3. The same advertisement was e-mailed to the nurses and CNAs two weeks prior to the scheduled in-services. The advance notice gave them a chance to be aware of the project and to make plans to attend an in-service.

The in-services took place on Fain 3 for four days at different times during a regular clinic day. Nurses and CNAs were given an IRB approved informational letter (Appendix C) that 
explained the project and were also asked to take part in an optional, confidential two question multiple choice pre in-service questionnaire (Appendix D) that offered insight into the nurses' baseline knowledge regarding ONS recommended treatment for CRF and the fatigue score that triggers the need for a treatment intervention on Fain 3. The tests did not contain any identifiers; completed pretests were placed by the participants into a drop box that was locked after completion. The in-service, which took 15 minutes, was held in a spare room in the clinic. The training plan is illustrated in Table 2.

Table 2

Nurse In-service Training Plan

\begin{tabular}{|l|l|}
\hline \multicolumn{1}{|c|}{ In-Service Objectives } & \multicolumn{1}{|c|}{ Content } \\
\hline $\begin{array}{l}\text { The nurse will define/describe CRF } \\
\text { condition and express the significance of } \\
\text { its incidence remove inactivity next line }\end{array}$ & $\begin{array}{l}\text { Definition/description of CRF, including signs } \\
\text { \& symptoms } \\
\text { Incidence of CRF }\end{array}$ \\
\hline $\begin{array}{l}\text { The nurse will state the potential effects of } \\
\text { inactivity }\end{array}$ & Effects of inactivity \\
\hline $\begin{array}{l}\text { The nurse will state the ONS treatment } \\
\text { recommendation for fatigue }\end{array}$ & Exercise as treatment for CRF \\
\hline $\begin{array}{l}\text { The nurse will state the fatigue score that } \\
\text { requires an intervention on Fain 3 }\end{array}$ & Fatigue score of $>4 / 10$ triggers intervention \\
\hline $\begin{array}{l}\text { The nurse will state the steps the patient } \\
\text { will take to determine which exercises they } \\
\text { will perform depending on their fatigue } \\
\text { level }\end{array}$ & $\begin{array}{l}\text { Determine what their fatigue level is: }>4 / 10 \text { or } \\
\text { moderate/severe: perform exercises in the CRF } \\
\text { brochure. } \\
\text { If fatigue is <4/10 or mild: perform exercises } \\
\text { recommended in the teaching session. }\end{array}$ \\
\hline $\begin{array}{l}\text { The nurse will describe/demonstrate the } \\
\text { recommended exercises }\end{array}$ & $\begin{array}{l}\text { Stretches, range of motion and exercises are } \\
\text { contained in the CRF brochure }\end{array}$ \\
\hline $\begin{array}{l}\text { The nurse will demonstrate documentation } \\
\text { of fatigue intervention on the revised } \\
\text { treatment sheet }\end{array}$ & $\begin{array}{l}\text { Revised treatment sheet, makes it simple for } \\
\text { the nurse to document their intervention: } \\
\text { 1. Provided CRF exercise brochure to the } \\
\text { patient } \\
\text { 2. Encouraged/reminded patient to perform } \\
\text { exercises (patient already had the brochure) } \\
\text { 3. Provided the brochure (again) and } \\
\text { encouraged its use }\end{array}$ \\
\hline
\end{tabular}


At the completion of the in-service, the staff was asked if any clarification of the material was necessary and questions were addressed. After completion of the in-service, the nurses and CNAs were asked to complete the same TWO question optional, confidential post-test. The tests were placed by the nurses in the same box immediately after completion that was then locked.

At a staff meeting two weeks following the in-services, nurses and CNAs were also asked to complete a confidential, optional survey of the in-service (Appendix E). It queried whether they felt the in-services adequately prepared them for providing CRF education and exercise instruction. Additionally, it sought input regarding the preparedness of the provider and the conditions and timing of the in-services. After the staff meeting, nurses gave completed forms to the Director of Outpatient and Cancer Services who placed the forms in a nine by twelve envelope, sealed it and later hand delivered it to the graduate researcher. The completed surveys were reviewed by the graduate researcher and placed with the questionnaires in the same locked box. Later after final review, the graduate researcher placed all the forms in a nine by twelve envelope that was labeled with the date and its contents; the envelope flap was sealed, signed and the envelope was placed in the office of the PI.

Outputs. Outputs are the changes that happen as a result of the activities. Subsequent to the CRF intervention in-services, nurses were thought to be prepared to provide patients who have fatigue levels of $>4 / 10$ an intervention for CRF. It was anticipated that the patients and their support person would receive CRF instruction and exercise directions in the clinic using the brochure. Patients would be instructed to bring the CRF brochure home and use it daily as a reference for exercising, and to hang the brochure in a visible place as a daily reminder to exercise. Additionally, as part of the intervention, the nurses would now have a simple method to document fatigue education. 
Outcome and Impacts. The outcome refers to the improvements that occur as a result of meeting the goals. Data can be used to measure achievement. Change in knowledge was measured by pre-post in-service test scores. Impacts are the intended or unintended change occurring in organizations, communities, or systems as a result of program activities. In this case, the student investigator and Fain 3 leadership were optimistic that Press Ganey scores on Fain 3 for fatigue education would show improvement, or at least steady values $>90 \%$, in the future months . The plan that was in place was that six months post implementation of the CRF intervention, the Director of Outpatient and Cancer Services would monitor Press Ganey scores for fatigue education. In addition to improved patient satisfaction scores, it was thought that educating patients in the community on CRF and the potential complications related to fatiguerelated inactivity may impact morbidity and mortality and improve the quality of life of involved individuals.

Next, the results will be presented. 


\section{Results}

Twenty-three of the twenty-eight nurses on Fain 3 attended the in-service and opted to take part in the two question, multiple choice pre and post in-service questionnaires. Each correct answer was worth 1 point. Table 3 illustrates the responses to the pre and post questions. Table 3

CRF pre and post in-service questionnaire results

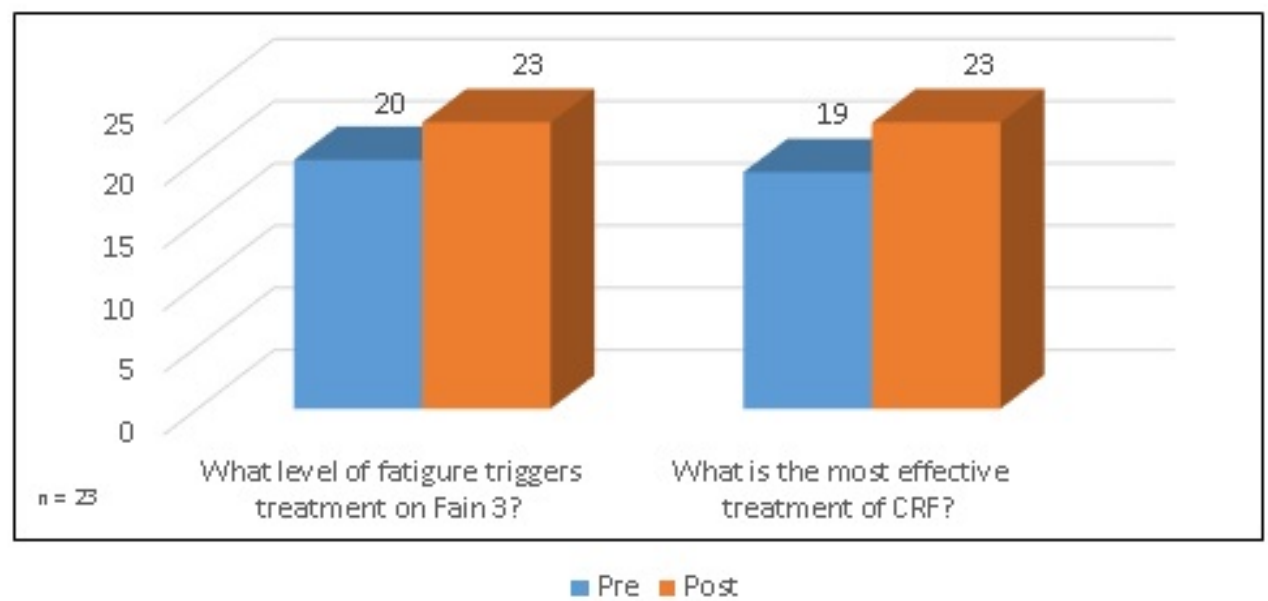

For the first question, the pre-test showed that 20 nurses of the 23 who participated in the test had the correct answer. The post-test revealed that all of the 23 nurses who participated in the test answered the question correctly. For question number two, the pre-test revealed that 19 nurses of the 23 who participated in the pre-test had the correct answer. The post-test also revealed that all of the 23nurses who participated in the post test answered correctly. Based on the pre-test/post-test results, the nurses showed an improvement in knowledge after attending the CRF in-service.

In addition, 13 of the Fain 3 nurses took part in the optional CRF intervention in-service evaluation survey (Appendix E). The survey consisted of fifteen questions using the Likert scale and two multiple response questions. In addition there was a comment section that asked for 
participants' opinions regarding the in-service or the CRF intervention/brochure. Six nurses offered anecdotal comments. The comments offered were:

- "The brochure is too complicated to explain to patients.”

- “The intervention is perfect for our patients, looking forward to using it more.”

- “I wish I had known that it was available already, I haven’t used it yet.”

- "The fatigue brochure is great, but we need to keep it with all the other papers so that it is easier to find. I had trouble finding it.”

- " "Very informative in-service and fatigue intervention.”

- " "It was hard to concentrate on the in-service because I had patients to take care of.” Next, is the summary and conclusion section. 


\section{Summary and Conclusions}

\section{Summary}

Over one million people are diagnosed with some form of cancer yearly. The most frequently experienced, yet seldom recognized, side effect of cancer or cancer treatment is fatigue. Otherwise known as cancer-related fatigue (CRF), this extreme tiredness often contributes to inactivity. Morbidity and mortality related to inactivity have been well documented in the literature (Ezzati et al., 2006; Halpin, Morales-Suárez-Varela \& Martin-Moreno, 2010; Warburton, Nichol \& Bredin, 2006). The Oncology Nursing Society (ONS) recommends that exercise is the only evidence-based intervention shown to be significant to combat CRF (National Guideline Clearinghouse, 2011). However, serious fatigue reduces participation in exercise. There needs to be an alternative that reduces deconditioning and other dangerous side effects of inactivity.

On Fain 3, an out-patient oncology clinic at The Miriam Hospital (TMH), a 247 bed Magnet hospital in Providence, RI, fatigue is a familiar complaint. Prior to this project being implemented, nursing practice for addressing CRF included education, encouraging exercise, and energy conservation. Leadership assessment of Fain 3 Press Ganey scores education had revealed erratic results. Press Ganey scores for fatigue education for 20112013 ranged monthly from 81.3 to97.7\% satisfaction. While a plan had been identified to address this, this investigator suggested that a needs assessment be conducted to further investigate the issues The needs assessment identified opportunities for improvement in the nursing management of CRF. 
The purpose of this project was to develop and implement a nurse-driven, exercisebased program as an intervention to combat severe CRF that would otherwise limit daily activity. Dorothea Orem's Self Care Theory (Orem, 1980) was used to guide the patient education component of this project, and the Logic Model was specifically used to visualize and operationalize the program development.

Permission to implement the project was obtained from the Lifespan and Rhode Island College IRBs, the Director of Out-patient and Oncology Services, and the Oncology physicians. The student investigator developed a brochure comprised of CRF education, lower extremity exercises, and an exercise log. Content development was guided by the literature and with input from others. Exercises for the brochure were obtained from the Director of Physical Therapy at TMH. These exercises were part of a mobility program used elsewhere in the hospital, and were adapted to benefit the oncology population.

After developing the brochure, the next step included educating the nurses and unitbased CNAs as to its' contents. In-services were advertised by posting a notice on the unit as well as by e-mail sent out two weeks prior to their starting. One week before making the brochures available, in-services were held on Fain 3 for four days, before and during a regular clinic day. The 15 minute in-service included a review of CRF, reasons for implementing the change, the contents of the CRF brochure, and how to document its' use on the clinic treatment sheets. Two weeks after the project was implemented, a voluntary evaluation survey was distributed to obtain feedback on the in-services as well as use of the brochure. 
Eighty-two percent (23 out of 28) of the Fain 3 nursing staff participated in the CRF in-services. Twenty-one nurses and two CNAs completed the two question pre and post in-service questionnaire. Post-tests scores demonstrated an improvement in knowledge by attendees. Optimistically, patients on Fain 3 who acknowledge a fatigue score of >4/10 will consistently be provided the CRF brochure.

\section{Limitations}

The study had several limitations. Although the range of motion, stretches, and exercises are pictured, the brochure directions and education are written in English. If a language barrier exists, utilizing alternatives such as employing the patient's Englishspeaking family or support person is recommended, as well as interpreter services.

The in-services took place on the unit during normal clinic hours, so the in-services were restricted to a 15 minute time period. Having further time would have allowed for additional discussion and input.

IRB approval was not obtained to allow accessibility to the patient's charts after implementation of the project. Ideally, a follow up chart review would be performed to assess documentation of appropriate use of the CRF intervention for fatigue scores of $>4 / 10$. Likewise, due to the short term nature of this project, the investigator was not able to assess actual use of the brochure over time. Nurses' continued cooperation in distributing the brochure and documenting such will be essential. The Director of Outpatient and Cancer Services intended to follow-up on the Press Ganey fatigue education scores at six and 12 months. Finally, no attempt was made to obtain input from the patients themselves about the usefulness of the brochure. Further work is indicated. 


\section{Conclusion}

Cancer-related fatigue is more than being “tired”. It’s a condition that, if left untreated, can lead to life altering and/or life threatening conditions. In this case, CRF was often unrecognized by the sufferer and clearly overlooked and under treated by the healthcare team. Optimal treatment as recommended by the ONS is exercise. Based on this project, this student investigator concludes that pro-active exercise programs should be routinely and consistently recommended for cancer patients. For them, exercise should not be perceived as an optional activity, but viewed as a vital part of their day as common as eating, washing or grooming. The challenge will be that health care professionals need to not only be knowledgeable about the value of exercise for managing CRF, but also need to work closely with impacted patients to determine how exercise can be successfully implemented into their lives. Nurses need to be diligent in identifying patients with significant fatigue and faithful in promoting the benefits of exercise and distributing CRF intervention brochure to their patients. These strategies will potentially assist oncology patients with CRT to effectively manage this potentially debilitating condition.

Implications for the Advanced Practice Nurse will be addressed next. 


\section{Recommendations and Implications for Advanced Nursing Practice}

One of the major expectations for the APRN is to be a facilitator of change when practices in health care are determined to not be 'best practices' and thus inefficient or inappropriate in promoting well-being. As research continues to provide updated information, the need for practice and policy change becomes a priority. For example, recommendations for treating CRF have shifted from advising energy conservation and rest to the best practice recommendation by ONS for exercise (National Guideline Clearinghouse, 2011). Advanced practice nurses should take a leadership role in changing practice and associated policies by identifying a need, strategizing a plan, identifying stakeholders, and providing them with the most updated best practice recommendations.

Advanced practice nurses have the ability to impact policy at the local, state, and national levels. Active involvement in professional and policy making organizations is critical. Such groups as the American Cancer Society and the Oncology Nurses Association have been instrumental in advancing research and improving the care of people with cancer. Master’s prepared nurses can play a critical role by actively participating in these groups and lobbying for continued understanding of syndromes such as CRF.

Research is another area in which the APRN can be influential. There are always questions or uncertain procedures clinically, that require scrutiny for possible improvement or confirmation of best practice. However, when research on the subject is lacking, the APRN should be a competent facilitator. The APRN should encourage 
nurses to be diligent and utilize research in their practice and patient education. This can be accomplished either alone or in conjunction with other members of the interdisciplinary team to provide best practice support for policy and procedure. There is a need for further nursing research related to CRF. Research with larger samples, more robust research designs, and testing exercise as well as other supportive interventions is needed.

Advanced practice nurses, particularly CNSs, possess the evidence based knowledge to guide nurses' informal learning at the bedside as well as more formal staff education efforts. Clinical nurse specialist presence in the clinical area provides teachable moments for real time education. In regard to $\mathrm{CRF}$, which is a complex condition, patients as well as nurses seldom recognize the myriad of symptoms that can be associated with fatigue, including forgetfulness, loss of concentration, heaviness of extremities and emotional disturbances. . The APRN can be pivotal in identifying these patient education opportunities and alerting nurses to these teaching occasions. The CNS is prepared to lead, support, and empower patients, nurses, and other members of the team to provide optimal care that will result in favorable outcomes. The APRN can act as a consultant as well as a role model by assisting nurses to identify and investigate a problem and assist them in locating sources and gathering evidence that will provide proper understanding or a solution to a problem.

The roles and responsibilities of the APRN are many and varied: expert clinician; clinical consultant; team member and leader; educator; innovator; user and facilitator of 
evidence based practice, advanced practice nurses are invaluable to health care settings assuring the quality and safety for all. 


\section{References}

Al-Majid, S. \& Waters, H. (2008). The biological mechanisms of cancer-related skeletal muscle wasting: the role of progressive resistance exercise. Biological Research for Nursing,10(1), 7-20. DOI: 10.1177/1099800408317345

Andreyev, H. J., Norman, A. R., Oates, J., \& Cunningham, D. (1998). Why do patients with weight loss have a worse out-come when undergoing chemotherapy for gastrointestional malignancies? European Journal of Cancer, 34, 503-509.

Attaix, D., Ventadour, C., Codran, A., Bechet, D., Taillandier, D., \& Combaret, L. (2005). The ubiquitin-proteasome system and skeletal muscle wasting. Essays in Biochemistry, 41, 173-186.

Blaney, J., Lowe-Strong, A., Rankin, J., Campbell, A., Allen, J. Cracey, J. (2010). The cancer rehabilitation journey: barriers to and facilitators of exercise among patients with cancer-related fatigue. Physical Therapy, 90(8), 1135-1146.

Berger, A.M., \& Higginbotham, P. (2000). Correlates of fatigue during and following adjuvant breast cancer chemotherapy: A pilot study. Oncology Nursing Forum, 27, 1443-1448.

Cleveland Clinic Cancer Center (2005). Cancer and cancer fatigue. Chemocare.com. Retrieved from http://www.chemocare.com/managing/fatigue_and_cancer_fatigue.asp

Dimeo, F. C. (2001). Effects of exercise on cancer-related fatigue. Cancer, 92(6 Supplement), 1689-1693. Retrieved from http://www.ncbi.nlm.nih.gov/pubmed/11598888 
Escalante, C., (2012). Cancer-related fatigue: prevalence, screening and clinical assessment. Retrieved from www.uptodate.com

Ezzati, M.,Vander Hoom, SV., Lopez, A. D., Danaei,G., Rodgers, A., Mathers, C. D., \& Murray, C. J. L. (2006). Comparative quantification of mortality and burden of disease attributable to selected risk factors. Global burden of disease and risk factors (Chapter 4). Retrieved from http:/files.dcp2.org/pdf/GBD/GBD04.pdf

Friedenreich, C.M., \& Courneya, K.S. (1996). Exercise as rehabilitation for cancer patients. Clinical Journal of Sport Medicine, 6, 237-244.

HCPro (2012). Complications from immobility by body system. Retrieved from http://www.hcpro.com/LTC-286850-10704/Complications-from-immobility-bybody-system.html

Halpin, H., Morales-Suárez-Varela, M. \& Martin-Moreno, J. (2010). Chronic disease prevention and the new public health. Public Health Reviews, 32(1), 120-154. http://www.publichealthreviews.eu/upload/pdf_files/7/08_Chronic.pdf.

Hormeber, M., Fischer, I., Dimeo, F., Ruffer, J. U. \& Weis, J. (2012). Cancer-related fatigue: epidemiology, pathogenesis, diagnosis, and treatment. Deutsches Aerzteblatt International, 109(9), 161-172. doi: 10.3238/arztebl.2012.0161

Journal of Supportive Oncology (2007). Watch for deconditioning in cancer patients and prescribe exercise. Retrieved from http://www.oncologypractice.com/jso/journal/articles/0502094.pdf

Knowles, M. S. (1970). What is andragogy in The modern practice of adult education: From pedagogy to andragogy, (pp. 40-59). New Jersey: Prentice Hall Regents 
Retrieved from:

http://www.cumc.columbia.edu/dept/medicine/hospitalists/downloads/cc4_article s/Education\%20Theory/Andragogy.pdf

McNeely, M., Campbell, K., Rowe, B., Klassen, T., Mackey, J., \& Courneya, K. (2006). Effects of exercise on breast cancer patients and survivors: a systematic review and meta-analysis. Canadian Medical Association Journal, 175(1), 34-41, doi: 10.1503/cmaj.051073.

Mock, V. (2003). Cancer-related fatigue. In C. W. Given, B. Given, V. L. Champion, S. Kozachik, \& D.N. DeVoss (Eds), Evidence-based cancer care and prevention: Behavioral interventions (Chapter 8). Retrieved from Helin, eISBN: 9780826115737

Mock, V., St. Ours, C., Hall, S., Bositis, A., Tillery, M., Belcher, A., Krumm, S., \& McCorkle, R. (2007) Using a conceptual model in nursing research-mitigating fatigue in cancer patients. Journal of Advanced Nursing. 58(5), 503-512, DOI: 10.1111/j.1365-2648.2007.04293.x.

National Cancer Institute. (2012). Fatigue. Retrieved from http://www.cancer.gov/cancertopics/pdq/supportivecare/fatigue/HealthProfession al/page1/AllPages\#1

National Guideline Clearinghouse. (2011). Retrieved from http://guideline.gov/content.aspx?id=15698\#top

National Comprehensive Cancer Network. (2014). NCCN Clinical Practice Guidelines in Oncology $^{\mathrm{TM}}$ : Cancer-related fatigue. Retrieved from 
http://www.pfizerpro.com/resources/minisites/oncology/docs/NCCNFatigueGuide lines.p df

Ng, A.V. (2010). The underrecognized role of impaired muscle function in cancer-related fatigue. Journal of Supportive Oncology. 8(4), 177-8.

Nursing Theories. (2012). Dorothea Orem’s self-care theory. Retrieved from http://currentnursing.com/nursing_theory/self_care_deficit_theory.html

ONS (2008). Putting evidence into practice: fatigue. Retrieved from http://www.ons.org/Research/PEP/media/ons/docs/research/outcomes/fatigue/sam plechapter.pdf

Orem, D. E. (1980). Nursing: Concepts of practice ( ${ }^{\text {nd }}$ ed.). New York: McGraw-Hill Book Company.

Peterson, D.(2012). Overview of the benefits and risks of exercise. UpToDate. Retrieved from http://www.uptodate.com/contents/search?search=the+benefits+and+risks+of+exe rcise\&sp=0\&searchType=PLAIN_TEXT\&source=USER_INPUT\&searchControl =TOP_PULLDOWN\&searchOffset=

Ream, E., \& Richardson, A. (1999). From theory to practice: Designing interventions to reduce fatigue in patients with cancer. Oncology Nursing Forum, 26, 1295-1303.

Renpenning, K. M. \& Taylor, S. G. (Eds.). (2003). Self-care theory in nursing: selected papers of Dorothea Orem. New York, NY: Springer Publishing Company. http://www.scribd.com/doc/19208337/Self-Care-Theory-in-Nursing-SelectedPapers-of-Dorothea-Orem 
Stricker, C. T., Drake, D., Hoyer, K.A., Mock, V. (2004). Evidenced-based practice for fatigue management in adults with cancer: exercise as an intervention. Oncology Nursing forum, 31(5), 963-976).

University of Georgia. (2008). Low-intensity exercise reduces fatigue symptoms by 65 Percent, study finds. ScienceDaily. Retrieved from www.sciencedaily.com/releases/2008/02/080228112008.htm

US Department of Health and Human Services (HHS), Office of Disease Prevention and Health Promotion. (2008). Physical activity guidelines for Americans. Washington: HHS. Retrieved from http://www.healthypeople.gov/2020/topicsobjectives2020/overview.aspx?topicid $=33$

Velthuis, M.J., Agasi-Idenburg, S. C., Aufdemkampe, G., Wittink, H. M.(2010). The effect of physical exercise on cancer-related fatigue during cancer treatment: a meta-analysis of randomised controlled trials. Clinical Oncology. 22(3). 208-221.

Wanchai, A., Armer, J.M., \& Stewart, B. R. (2011). Nonpharmacologic supportive strategies to promote quality of life in patients experiencing cancer-related fatigue: a systematic review. Clinical Journal of Oncology Nursing, 15(2), 203-214.

Warburton, D.E.R, Nicol, C.W. \& Bredin, S.S.D. (2006). Health benefits of physical activity: the evidence. Canadian Medical Association Journal (CMAJ), 174(6), 801-808. Retrieved from http://www.cmaj.ca/content/174/6/801.full.pdf+html W.K. Kellogg Foundation (2004). Logic model development guide. Retrieved from 
http://cpmcnet.columbia.edu/dept/pi/ppf/LogicModel.pdf

Wu, H.S., Dodd, M. J., \& Cho, M.H. (2008). Patterns of fatigue and effect of exercise in patients receiving chemotherapy for breast cancer. Oncology Nursing Forum, 35(5), E90-E99. 

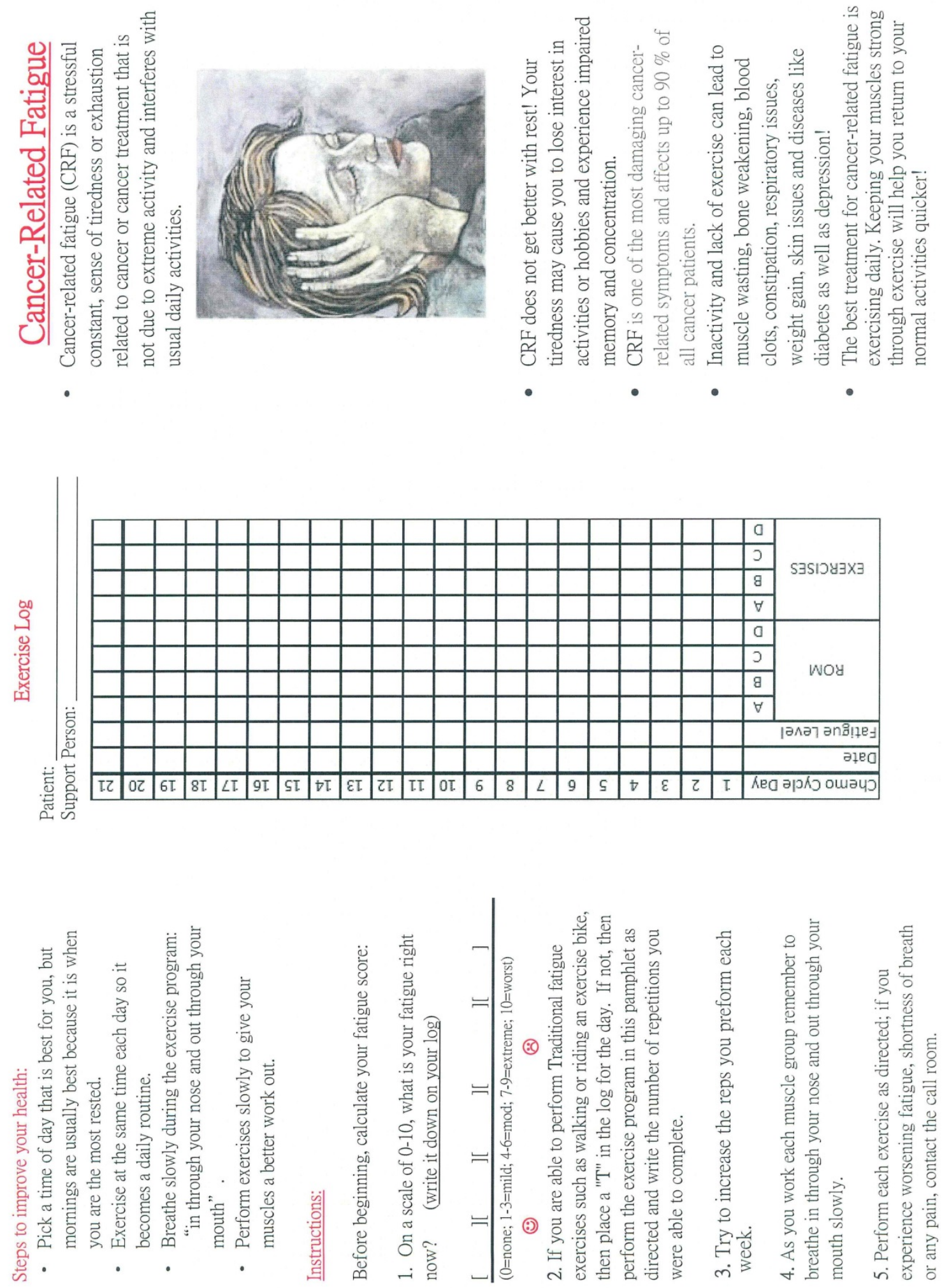


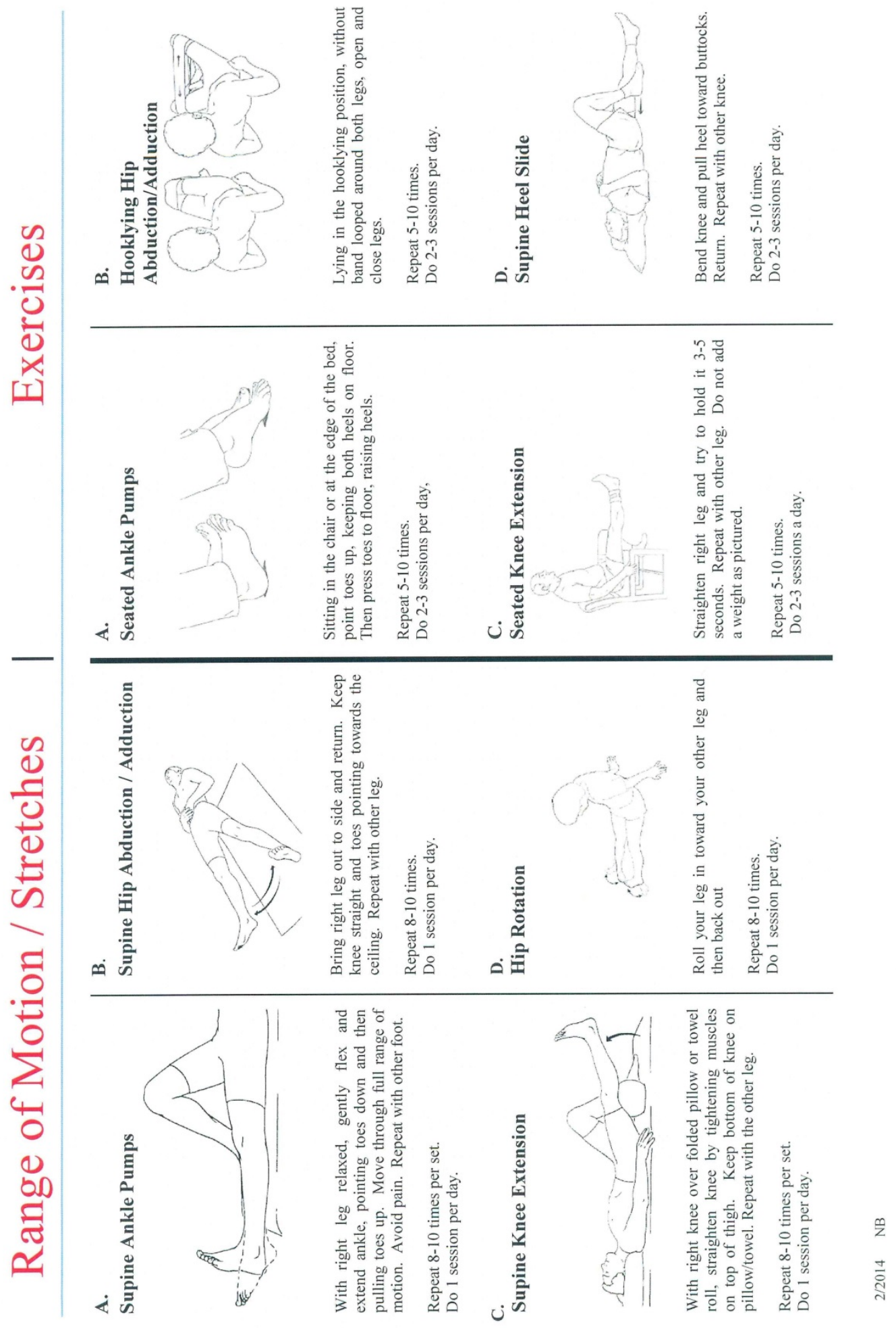




\section{COMING SOON: NEW FATIGUE INTERVENTION!}

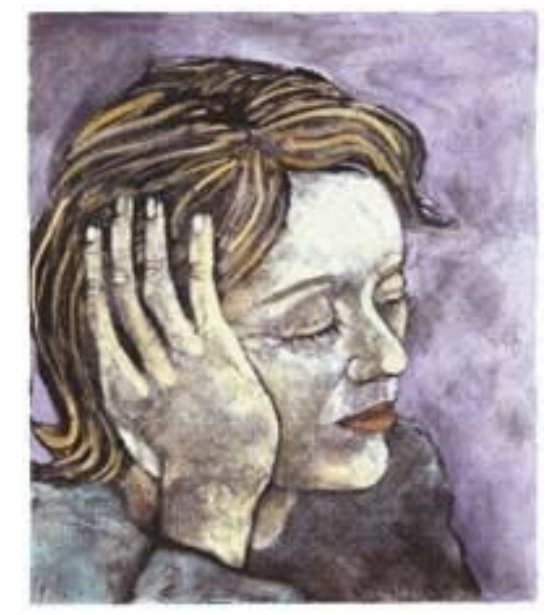

Who:

All Fain 3 Nurses

What:

New fatigue intervention program proposed for patients with $>4 / 10$ fatigue.

When: $\quad$ January 20, 2014

Where: $\quad$ Fain 3 clinic

Why:

An intervention to offer to your patients when their extreme fatigue $(>4 / 10)$ prevents them from participating in their expected exercises or daily activities.

How:

There will be scheduled informational in-services the week of January $13^{\text {th }}$. You only need to attend one. Before and after the in-service, you will be asked to complete questionnaires and an in-service evaluation, that are optional and confidential. Completion of the questionnaires is not required for in-service attendance. 


\section{Informational Letter}

You are being invited to take part in a Lifespan research project entitled 'A Nurse-Driven, ExercisedBased Intervention for Patients with Cancer-Related Fatigue (CRF) When Severe Fatigue Interferes with Daily Activity'. If you participate, you will be involved in testing an accurate way to document use of a fatigue intervention brochure on patients who have fatigue levels greater than 4 on a 10 point scale. Nancy Opaluch-Bushy, a graduate student at RIC, will be implementing this project in conjunction with Dr. Cynthia Padula, the faculty advisor.

Participation in this research project will involve completing a voluntary, confidential two item questionnaire at two time points: 1) prior to attending a fatigue in-service and 2) immediately following the fatigue in-service. Completion of the questionnaire is not required for in-service attendance. Finally, after one week of implementing the brochure intervention on Fain 3, you will be asked to complete a confidential evaluation of the fatigue in-service.

While participation in the research project is voluntary, Michelle Carpentier, Director of Ambulatory and Cancer Services, has supported attendance at the fatigue in-service as this intervention may become part of unit procedure. The fatigue in-service will be offered for one week at several times for your convenience. It will take place on Fain 3 during one of your regularly scheduled shifts. During the inservice, you will be oriented to the brochure-how and when to use it and how to document that it was given to the patient. The in-service will take about 15 minutes. The in-service is being offered to you regardless of your participation in the research project. When the research project is implemented, you will be asked to review the brochure with any patient who has a fatigue score of $>4 / 10$ and document that you distributed the brochure intervention. The patients will take the brochure home with them for use as a guide to fight fatigue with information and exercises.

You are free to choose whether or not to fill out the pre and post in-service questionnaire and the evaluation of the in-service. If you participate in this research study, none of the information you provide will have your name or any number on it that will identify you personally. Any completed forms will be kept in a locked box and only the student researcher will have access. All forms will be placed in a dated, locked box and kept in Dr. Padula's office for 3 years after which time all documents will be shredded.

There are minimal to no risks to participating in the project. We hope that use of the brochure will help us provide better care to our patients.

If you have any questions about this study, please feel free to contact me at nbushy_6107@ric.edu or Dr. Padula atcpadula@ric.edu.

If you have any questions about your rights as a research subject, please feel free to call our Office of Research Administration manager, Patricia Houser, at 444-2099. In addition, you may contact Dr. Christine Marco, Chair of the Rhode Island College Institutional Review Board at IRB@ric.edu, or by phone at 401-456-8598.

Thank you for participating in the project.

Sincerely, Nancy Opaluch-Bushy Master of Science in Nursing student, Rhode Island College School of Nursing 
Pre/Post In-service Questionnaire

\section{Cancer-Related Fatigue Questionnaire}

1. On Fain 3, what level of fatigue triggers treatment intervention(s)?
A. $\geq 2 / 10$
B. $\geq 4 / 10$
C. $>6 / 10$
D. $\geq 8 / 10$

2. What is the most successful, ONS recommended treatment for cancer-related fatigue?
A. Rest/sleep
B. Energy conservation
C. Exercise
D. Improve nutrition 


\section{CRF In-service/Intervention Evaluation}

1. I have used the CRF intervention brochure for patients with fatigue $>4 / 10$. $\quad N \quad Y$ If not, why

2. Optional Comments regarding CRF In-Service and/or CRF Intervention Brochure: 